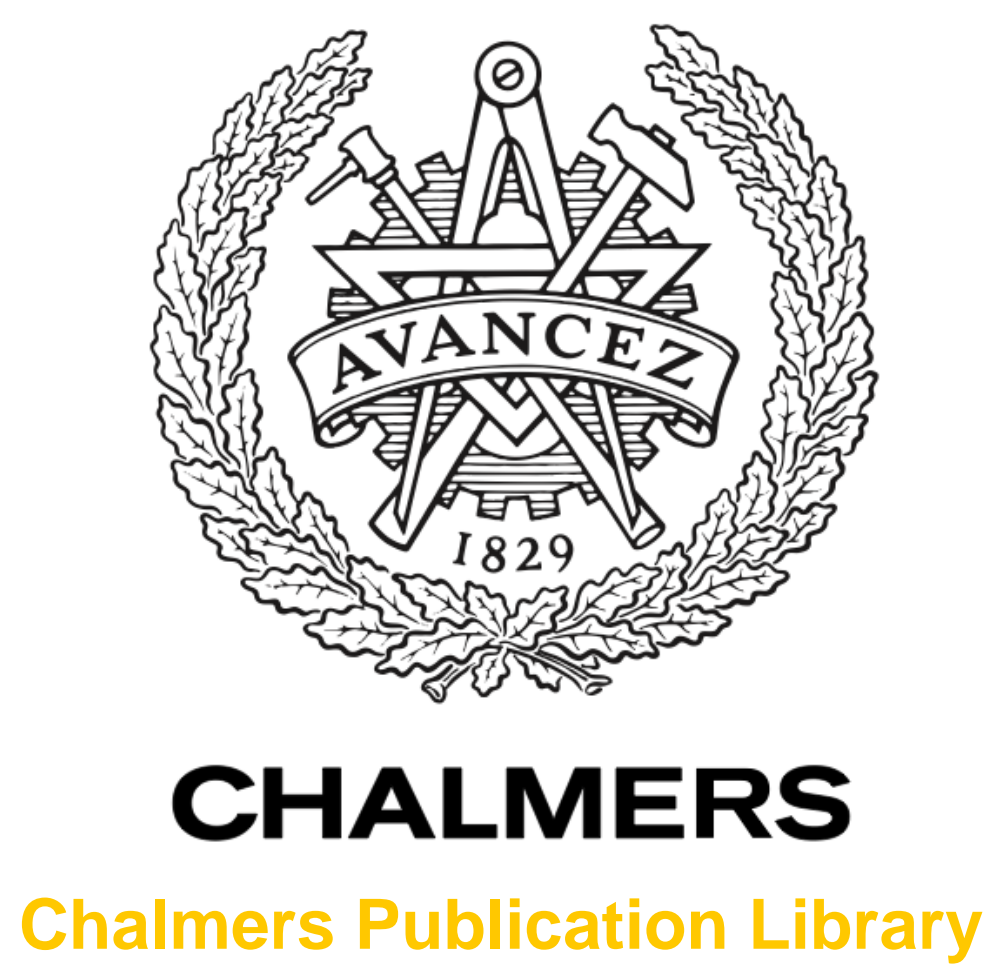

Four levels to assess anchorage capacity of corroded reinforcement in concrete

This document has been downloaded from Chalmers Publication Library (CPL). It is the author's version of a work that was accepted for publication in:

Engineering Structures (ISSN: 0141-0296)

Citation for the published paper:

Tahershamsi, M. ; Fernandez Perez, I. ; Zandi Hanjari, K. et al. (2017) "Four levels to assess anchorage capacity of corroded reinforcement in concrete". Engineering Structures, vol. 147 pp. 434-447.

http://dx.doi.org/10.1016/j.engstruct.2017.06.024

Downloaded from: http://publications.lib.chalmers.se/publication/250929

Notice: Changes introduced as a result of publishing processes such as copy-editing and formatting may not be reflected in this document. For a definitive version of this work, please refer to the published source. Please note that access to the published version might require a subscription. 


\title{
Four Levels to Assess Anchorage Capacity of Corroded Reinforcement in Concrete
}

\author{
Tahershamsi M. ${ }^{1}$, Fernandez I. ${ }^{1}$, Zandi K. ${ }^{1,2}$, Lundgren K. ${ }^{1}$
}

\begin{abstract}
${ }^{1}$ Department of Civil and Environmental Engineering, Division of Structural Engineering, Concrete Structures, Chalmers University of Technology, 412 96, Gothenburg, Sweden
\end{abstract}

${ }^{2}$ Material Group, CBI Swedish Cement and Concrete Research Institute, 501 15, Borås, Sweden

Keywords

Natural corrosion, Modelling, FE analysis, Anchorage, Bond, Reinforced concrete, Assessment

\section{Highlights}

- Four levels of analyses are, for the first time, compared with each other and to tests of naturally corroded beams. Thereby, the knowledge gained from advanced modelling is brought to engineering practice.

- The 3D Non-Linear FE analyses including bond and corrosion models, yield results consistent with the observations in the experiments

- The 3D Non-Linear FE analyses considering 1D bond-slip relations are useful to describe the structural behaviour

- $1 \mathrm{D}$ bond-slip model is useful for the estimation of the anchorage capacity in damaged specimens

- The simplified engineering approach underestimates the capacity in both corroded and non-corroded specimens

\begin{abstract}
Corrosion of reinforcement affects anchorage capacity. In this study, four levels of analyses were, for the first time, compared with each other and to tests of naturally corroded beams. In the most advanced approach, three-dimensional non-linear finite element (3D NLFE) analyses employing previously developed bond and corrosion models were carried out. These analyses agreed well with the experiments in terms of crack pattern and maximum load capacity. The next approach consisted of 3D NLFE analyses with a pre-defined bond-slip relation between concrete and reinforcement, resulting in reasonable agreement; however, the anchorage capacity was overestimated and the crack pattern deviated from the experiments. At the next level, the bond-slip relation was used together with a measured available anchorage length, and the anchorage capacity was obtained by numerically solving the one-dimensional differential equation; the results were reasonably close to the experiments. In the most simplified approach, a constant bond stress was assumed together with the available anchorage length measured, which underestimated the capacities. In conclusion, the more advanced analyses provide reliable information regarding the structural behaviour, while the two simplified methods are well suited for use in practice.
\end{abstract}




\section{$1 \quad$ Introduction}

The corrosion of steel reinforcement is one of the main deterioration issues in Reinforced Concrete (RC) structures. The study of corrosion effects is crucial for a better understanding of the structural behaviour of existing deteriorated concrete structures [1]-[3]. The corrosion process transforms parts of steel reinforcement into rust. This process leads to a reduction of the steel cross section affecting also its main mechanical properties [4]-[8]. However, the most severe effect of reinforcement corrosion is the volume increase of corrosion products causing splitting stresses along corroded reinforcement, which results in cracking and spalling, thus changing the bond properties between steel and concrete [9]-[13].

The bond mechanism is the transfer of stresses action between reinforcement and concrete, which makes it possible to anchor reinforcement in concrete. Bond action generates inclined forces, which radiate outwards in the concrete. The inclined stress is often divided into a longitudinal component, denoted the bond stress, and a radial component, denoted normal stress or splitting stress. The inclined forces are balanced by tensile ring stresses in the surrounding concrete, as explained by Tepfers [14]. If the tensile stress becomes larger than the tensile strength of the concrete, longitudinal splitting cracks will form in the concrete. This type of failure is called splitting failure. When the concrete surrounding to the reinforcement bar is well-confined, a pull-out failure characterised by shear cracking between the adjacent ribs is obtained; this is the upper limit of the bond strength. A common way to describe the bond behaviour is by relating the bond stress to the slip, that is, the relative difference in movement between the reinforcement bar and the concrete. However, as made clear above, the bond versus slip relationship is not a material parameter; it is closely related to the structure. Furthermore, as the bond depends on the structure's ability to carry splitting stresses, possible cracking or spalling due to corrosion will influence the bond to a large extent.

Many researchers have studied the effect of corrosion on bond deterioration. Several studies have investigated parameters which may influence bond and anchorage capacity of corroded structures; see [15]-[20]. These studies led to the development of different empirical, analytical and numerical models to assess the bond and anchorage behaviour of corroded reinforcement; see [21]-[27]. These models were developed based on different simplifying assumptions; thus, results with different levels of accuracy can be obtained using such models to assess the effect of corrosion on residual strength. However, it is rare to find comparisons between different models, especially on how capable models on different levels of detailing are compared to each other. The aim of this paper was to study and compare different methods to assess the anchorage capacity of naturally corroded RC structures. The assessment methods were based on four different levels of detailing and accuracy, ranging from advanced models suited for research to a simplified engineering approach suited for daily engineering work; see Figure 1. Thereby, we can bring the knowledge gained from research into simplified models that can be of use in engineering practice.

The modelling approaches are organized from the most advanced to simplified ones as follows:

- Level IV: Using three-dimensional non-linear finite element (3D NLFE) analyses employing previously developed bond and corrosion models. This level of analysis is well suited to research purposes, describing and understanding the structural effects of corrosion. 

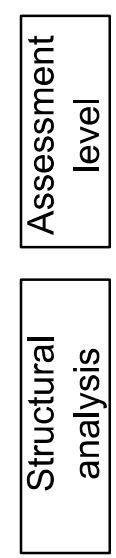

Figure 1.
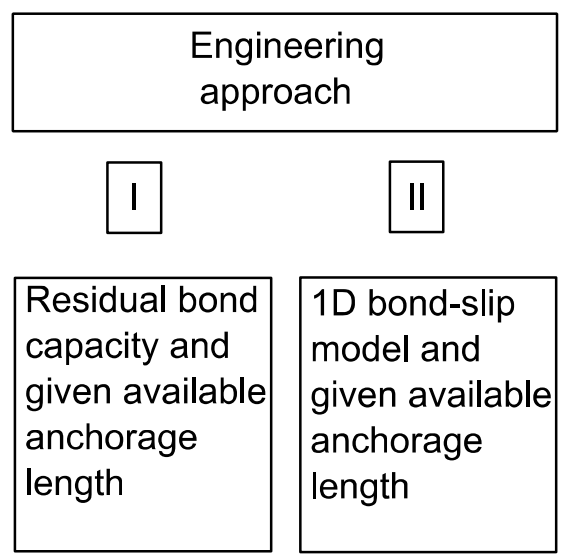

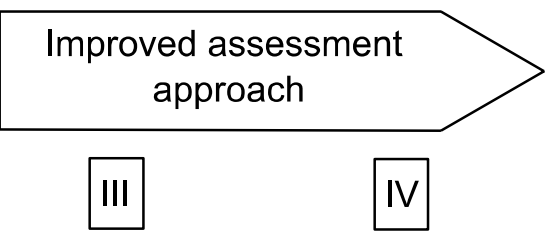

3D FE

analysis with

1D bond-slip

3D FE

analysis

including bond

and corrosion

models

- Level III: Using 3D NLFE analyses with a pre-defined one-dimensional (1D) bondslip relation between concrete and reinforcement. This level of modelling cannot directly take into account the splitting effects of the reinforcement slip and the expansion of corrosion products; these effects are instead accounted for by modifying the $1 \mathrm{D}$ bond-slip relation given as input.

- Level II: Using a 1D bond-slip model and a given available anchorage length. The anchorage capacity was obtained by numerically solving the $1 \mathrm{D}$ differential equation along the available anchorage length.

- Level I: Using a simplified approach where the residual capacity of the bond-slip model is used together with a given available anchorage length. As the bond stresses are assumed to remain constant over the available anchorage length, the anchorage capacity can be directly calculated as in commonly used engineering approaches.

In general, existing models of bond for corroded reinforcement have been calibrated based on experimental investigations of artificially corroded specimens. However, there are reasons to believe that the deterioration caused by natural corrosion does not have the same effects on the structural behaviour as the deterioration caused by artificial corrosion [28], [29]. Thus, it is doubtful whether the results from these models can be reliably applied to structures in the field. Therefore, the results of the four different analysis methods were compared to the experiments of natural corrosion in Tahershamsi et al. [30] to study the accuracy of each assessment method.

\section{$2 \quad$ Materials and experimental program}

Tests on naturally corroded reinforced concrete beams were carried out in an earlier work by Tahershamsi et al. [30]. A condensed description of the tests is given in the following sections.

\subsection{Test setup and specimen description}

Specimens were taken from RC edge beams of a steel girder bridge with a concrete deck slab, Stallbacka Bridge in Sweden. During service life of the bridge, de-icing salt has been often applied on the bridge deck and thus chlorides from the de-icing salt had reached the steel bars 
in the concrete. For this reason, corrosion was considered to be the main cause of deterioration. Based on the damage patterns on the edge beams, the specimens were categorized into three different groups: Reference $(\mathrm{R})$ specimens without any visible crack, Medium $(\mathrm{M})$ damaged specimens with spalling cracks, and Highly $(\mathrm{H})$ damaged specimens with spalling of the cover. Tests were carried out in two series. The analyses at Levels III and IV presented in this paper are focused on six of the thirteen tests in the second test series described in [30]. The six tests chosen for analyses are two Reference, two Medium, and two Highly damaged specimens. The analyses at Levels I and II were performed for all thirteen specimens in the second test series. The geometrical specifications of the specimens and test setup are shown in Figure 2.

An indirectly supported four-point bending test configuration was used for the experiments. The test configuration was designed to secure an anchorage failure for beams with different degrees of corrosion damage in one common test setup [31]. More information about the test specimens and test setup are provided in [30], [32].

\subsection{Concrete properties}

During the experimental work, cores of suspension holes were drilled out. The concrete compressive strength, $f_{c}$, was obtained by testing the cylindrical concrete samples for every beam specimen. More details regarding the compressive tests are available in [30]. The average compressive strength of the cores from each specimen was used for all analyses; see Table 1. The elastic modulus $(E)$ used in the analyses, $24.0 \mathrm{GPa}$, was the average of the elastic modulus of three specimens evaluated in the first test series; for more details see [32]. The fracture energy was calculated from the compressive strength by means of the provisions given in fib Model Code 1990 [33]. The mechanical properties of concrete used in the analyses are provided in Table 1.
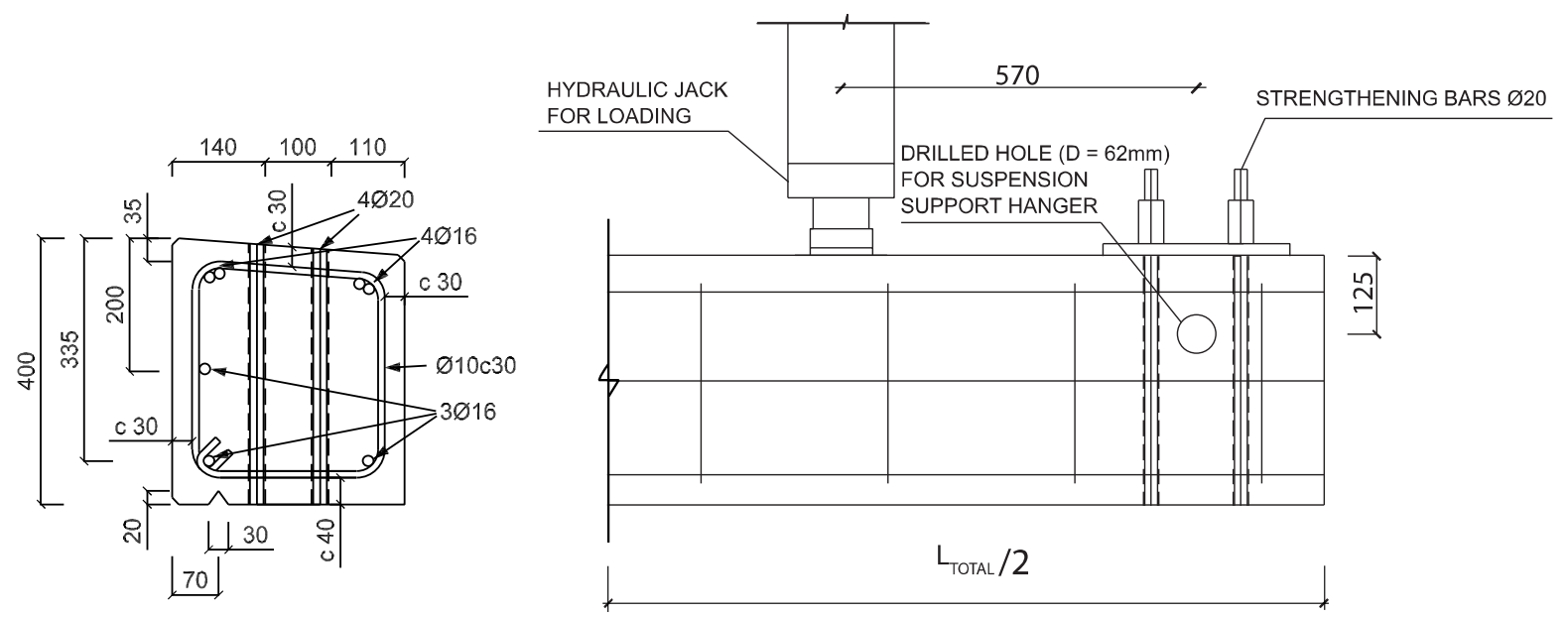

Figure 2. Schematic drawings of the cross section of the specimens tested and the test set-up. Measurements (in $\mathrm{mm}$ ) are nominal from drawings; the actual measurements varied slightly between the specimens and are provided in [30]. The cross-section to the left is shown as it was on the bridge; since the beams were tested upside down, the bundles were on the bottom in the test set-up to the right. 
Table 1. Mechanical properties of concrete, average cover and corrosion level of rebars from each specimen.

\begin{tabular}{cccccc}
\hline Specimen & $\begin{array}{c}f_{c} \\
{[\mathrm{MPa}]}\end{array}$ & $\begin{array}{c}f_{c t} \\
{[\mathrm{MPa}]}\end{array}$ & $\begin{array}{c}G_{F} \\
{[\mathrm{~N} / \mathrm{m}]}\end{array}$ & $\begin{array}{c}\text { Average } \\
\text { concrete cover } \\
{[\mathrm{mm}]}\end{array}$ & $\begin{array}{c}\text { Average weight } \\
\text { loss of the four } \\
\text { bars [\%] }\end{array}$ \\
\hline R4 & 48.1 & 2.8 & 90.0 & 54.5 & 0.0 \\
R6 & 47.0 & 2.7 & 88.7 & 54.0 & 0.0 \\
M4 & 46.4 & 2.7 & 87.9 & 55.0 & 2.8 \\
M5 & 40.5 & 2.3 & 79.9 & 53.0 & 1.8 \\
M7 & 39.1 & 2.2 & 77.9 & 54.0 & 2.3 \\
M8 & 49.2 & 2.9 & 91.6 & 47.5 & 0.7 \\
M9 & 41.2 & 2.3 & 80.8 & 50.0 & 0.7 \\
M10 & 42.6 & 2.4 & 82.7 & 52.5 & 2.4 \\
M11 & 40.6 & 2.3 & 80.0 & 59.8 & 4.6 \\
M12 & 37.6 & 2.1 & 75.8 & 59.8 & 2.3 \\
H5 & 45.9 & 2.7 & 87.2 & 51.8 & 3.7 \\
H6 & 38.4 & 2.2 & 76.9 & 56.3 & 3.6 \\
H7 & 37.2 & 2.1 & 75.2 & 53.8 & 3.5 \\
\hline
\end{tabular}

The tensile strength of concrete were not experimentally evaluated for each beam specimen, and thus had to be calculated from the compressive strength. However, the climatic data from a few weather stations located nearby Stallbacka Bridge, Trollhättan in Sweden, indicate that several freezing-thawing cycles are expected during one typical year. Given the age of the edge beams at the time they were collected, 30 years, the bridge may have been subjected to over a hundred freezing-thawing cycles, and consequently the tensile properties of concrete may have been significantly influenced. Therefore, the provisions in fib Model Code 1990 [33] were not directly applicable to calculate the tensile strength from the compressive strength. According to RILEM TC 176-IDC [34], [35], concrete is defined as damaged by freezing when the relative dynamic modulus of elasticity is less than $80 \%$. Earlier research has shown that after only 20 freeze-thaw cycles, the relative dynamic modulus of elasticity decreased to $80 \%$ [36] and that the influence of frost damage on tensile strength is more pronounced than on other properties of concrete [37], [38]. Thus, further investigation was made to quantify such an effect on the specimens used in this study.

Frost damage changes the microstructure of the concrete and thus microscopic technique and analysis of thin sections were used to find evidence of internal frost damage in the microstructure concrete core. Thin sections were cut from one Reference (R6) and one Highly damaged (H6) specimen. Figure 3 shows photographs of polished samples dyed with epoxy resin and fluorescent colour for the two samples; internal cracking can be seen in both samples.

The crack distribution was determined using image analysis of thin sections. Table 2 presents the characteristics of the crack density obtained from the microscope observations. The density of cracks is given in terms of number of cracks per unit area. The cracks are differentiated based on crack width in the cement paste and at the interfaces between aggregate and the cement. When compared with similar investigations for concrete with and without frost damage [39], it was concluded that samples R6 and H6 had internal cracks with a higher crack density than expected from concrete without frost damage. Sample H6 showed a higher crack density than sample R6. Based on these experiments, it can be confirmed that the cracks observed are associated with frost damage, and that the observed crack densities have had an influence on 
the tensile properties of concrete. Thus, the methodology prescribed in Zandi et al. [39] was applied to quantify the influent of frost damage on tensile strength of the specimen. Accordingly, the tensile strength used as input in the FE analyses was calculated from the relation proposed by Zandi et al. [39]:

$$
f_{c t}=0.027\left(f_{c}\right)^{1.2}
$$

where $f_{c t}$ is the tensile strength of the damaged concrete, and $f_{c}$ is the measured compressive strength of the damaged concrete in MPa. It should be noticed that these values of the tensile strength are about $25 \%$ lower than would have been calculated by the expression FIB [40], and also lower than the measured values in splitting tensile tests from the first test series, which was about 3.5 MPa [32]. However, this value was not considered to be representative for all specimens.

\subsection{Steel properties}

The longitudinal steel reinforcement and stirrups used in the construction of the edge beams were the ribbed hot-rolled bars of Ks60 $\phi 16$ and Ks40 $\phi 10$ Swedish type, respectively. The longitudinal reinforcement was tested in tensile tests; however, the results were scattered. As the test setup was designed to result in anchorage failure, no steel reinforcement reached yielding when the edge beams were tested; accordingly, the mechanical properties of the reinforcement were not as influential. Thus, input used in the analyses were taken from earlier tensile tests of the same type of reinforcement bars from the time when the Stallbacka Bridge was constructed. For the strengthening around the support holes, high yield Dywidag prestressing steel bars were used for which material properties were received from the manufacturer. The mechanical properties used in the analyses for longitudinal steel reinforcement, stirrups and high yield Dywidag pre-stressing steel are provided in Table 3.

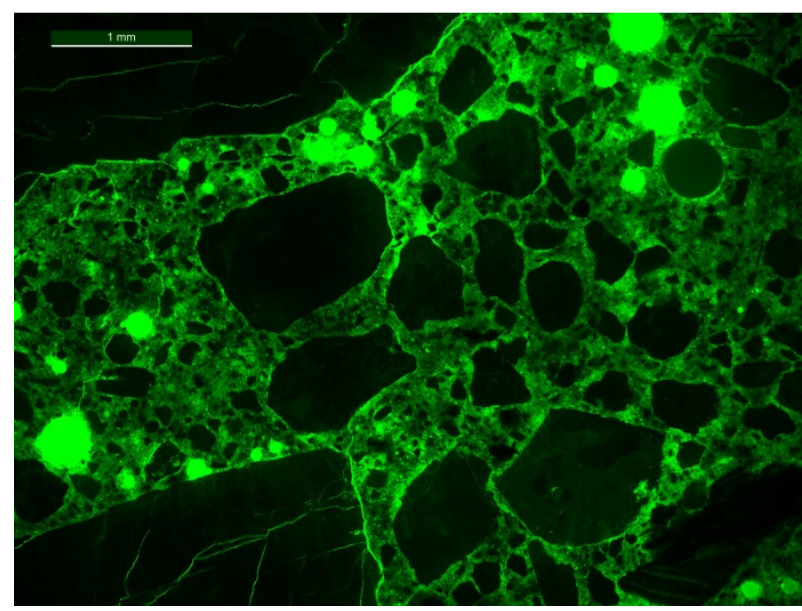

(a)

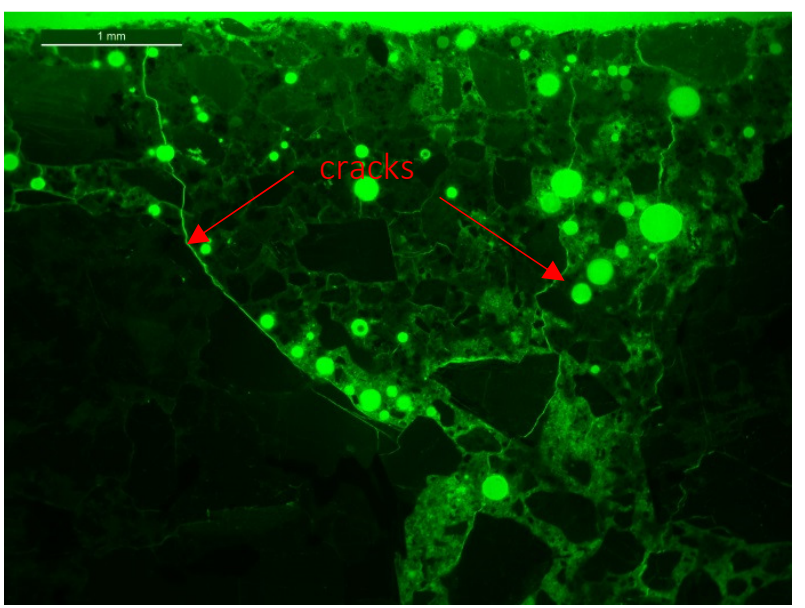

(b)

Figure 3. Distribution of cracks shown in pictures taken by a microscopic imaging system: (a) Reference beam (R6), (b) Highly damaged beam (H6). 
Table 2. Crack density in terms of number of cracks per unit area $\mathrm{mm}^{2}$ by analysis of thin sections; $w$ is crack width

\begin{tabular}{cccc}
\hline Concrete & $\begin{array}{c}\text { Coarse and } \\
\text { fine cracks } \\
0.01 \mathrm{~mm}<w \\
{\left[\mathrm{nr} / \mathrm{mm}^{2}\right]}\end{array}$ & $\begin{array}{c}\text { Micro crack } \\
w<0.01 \mathrm{~mm} \\
{\left[\mathrm{nr} / \mathrm{mm}^{2}\right]}\end{array}$ & $\begin{array}{c}\text { Adhesion } \\
\text { crack }\end{array}$ \\
\hline R6 & 0.0 & 0.1 & 0.7 \\
H6 & 0.0 & 0.5 & 1.6 \\
\hline
\end{tabular}

Table 3. Mechanical properties of the steel reinforcement used in the analyses

\begin{tabular}{lcccc}
\hline Steel type & $\begin{array}{c}f_{s y} \\
{[\mathrm{MPa}]}\end{array}$ & $\begin{array}{c}f_{s u} \\
{[\mathrm{MPa}]}\end{array}$ & $\begin{array}{c}E_{s} \\
{[\mathrm{GPa}]}\end{array}$ & $\begin{array}{c}\varepsilon_{u} \\
{[\%]}\end{array}$ \\
\hline Ks60 & 693 & 907 & 222 & 12.5 \\
Ks40 & 468 & 638 & 206 & 11.4 \\
$\begin{array}{l}\text { Strengthening } \\
\text { bars - Dywidag }\end{array}$ & 500 & 550 & 205 & 10.5 \\
\hline
\end{tabular}

\subsection{Corrosion measurements}

The longitudinal steel reinforcement bars on the tensile zone were extracted from the concrete members after the structural testing of the edge beams. The parts of the bars at the ends, where the anchorage failure took place, were cut to $580 \mathrm{~mm}$ long pieces. The bars were cleaned using the code recommendations [41]. The corrosion loss for each bar was calculated with respect to the average weight of the taken reference non-corroded reinforcement bars. The average values from the corrosion level of the bundled reinforcement bars, given in Table 1, were used in the analyses. Details about measured corrosion level in each bar can be found in Tahershamsi et al. [13].

\section{$3 \quad$ Modelling of anchorage failure of naturally corroded reinforced concrete beams}

In the following sections, the anchorage behaviour of naturally corroded reinforced concrete members was evaluated with four different modelling approaches, from enhanced FE analysis to simpler engineering approaches based on analytical solutions.

\subsection{Three-dimensional non-linear FE analysis employing bond and corrosion models (Level IV)}

At Level IV, 3D NLFE analyses were carried out, in which the effect of corroding steel reinforcement bars in concrete was modelled in detail by applying the bond and corrosion models developed by Lundgren et al. [26], [42]. The models describe the swelling effects of corrosion products through generating splitting stresses acting on concrete, as well as the influence on bond properties. The modelling method used is especially suited for detailed 3D FE analysis, using solid elements for both concrete and reinforcement. A short overview of the bond and corrosion models is provided in the following. 


\subsubsection{Overview of the bond model}

The model for the bond mechanism, initially formulated in [43] and later modified in [42], is a frictional model which uses elasto-plastic theory to define the relations between stresses and relative displacements. This model is suited for detailed 3D NLFE analyses where both the reinforcement and the concrete are modelled with solid elements. The bond model is assigned to $2 \mathrm{D}$ interface elements, at a surface between reinforcement bars and concrete, describing the relations between traction $\sigma$ and the relative displacement, $u$. The physical interpretations of the variables $\sigma_{n}, \tau, u_{n}$ and $u_{t}$ are shown in Figure 4.

The relation between the tractions, $\sigma$, and the relative displacements, $u$, is in the elastic range

$$
\left[\begin{array}{c}
\sigma_{n} \\
\tau \\
\tau_{r}
\end{array}\right]=\left[\begin{array}{ccc}
D_{11} & 0 & 0 \\
0 & D_{22} & 0 \\
0 & 0 & D_{33}
\end{array}\right]\left[\begin{array}{l}
u_{n} \\
u_{t} \\
u_{r}
\end{array}\right]
$$

where $D_{11}$ and $D_{22}$ describe the relation between relative displacements and stresses in the radial and slip directions, respectively. The third component, D33, corresponds to the relative displacements and stresses acting around the bar; this stiffness is chosen large enough to prevent rotation of the bar.

The yield surface is defined by two yield functions. The first function, $F_{1}$, describes the friction; in this study, the effect of adhesion was assumed to be negligible. The second yield function, $F_{2}$, describes the upper limit at a pull-out failure. It is determined from the crushing of the inclined compressive struts, which results from the bond action. The yield surface is shown in Figure 5. More details regarding the yield functions, flow rules and hardening laws have been provided in [42]. The input parameters used for the modelling have been chosen according to the values provided in [44].

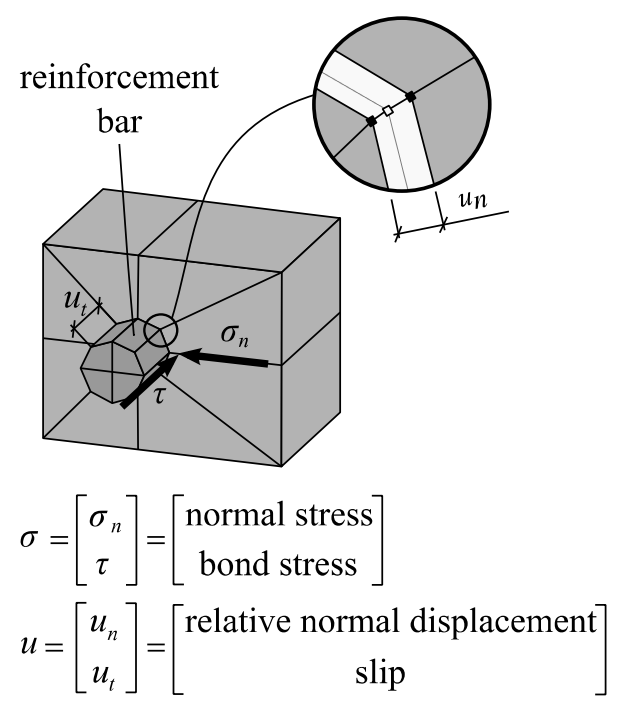

Figure 4. Physical interpretation of the variables $\sigma_{n}, \tau, u_{n}$ and $u_{t}$, modified from [42] 
Stress in the inclined compressive struts
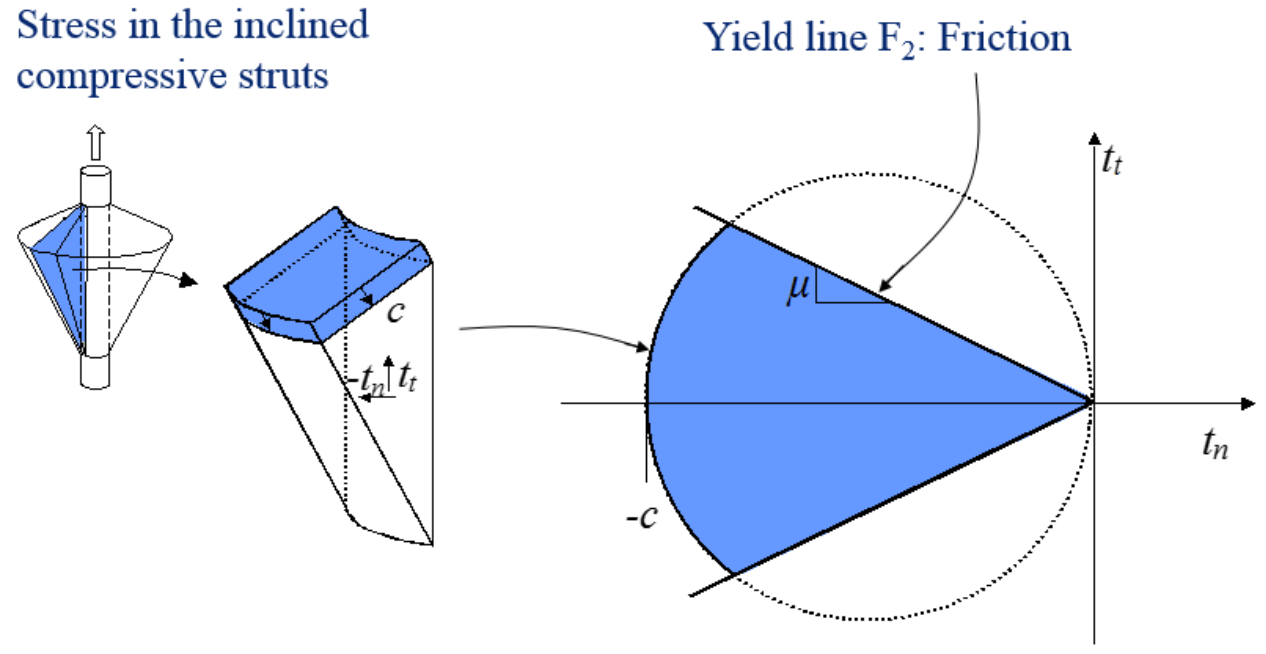

Figure 5. The yield surface of the model, modified from [43]

\subsubsection{Overview of the corrosion model}

The corrosion model used in the analyses was developed in [26] and further calibrated with several experimental results in [45], [46]. The model simulates the effect of corrosion as the volume increase of the corrosion products compared to the virgin steel. The volume of the corrosion products relative to the uncorroded steel, $v_{r s}$, and the corrosion penetration depth into the steel bar as a function of the time, $x(t)$, are used to calculate the free increase of the bar radius, $y$, which is the increase in radius including the corrosion products when the normal stresses are assumed to be zero. As the corrosion products are not free to expand, the real increase of the radius, $u_{n c o r}$, will be smaller than the free increase, and depend on both the mechanical behaviour in the rust, and of the structural resistance of the surrounding concrete. The corrosion process was modelled by taking time steps. Moreover, the coefficient of friction was assumed to decrease by the level of corrosion, as described in [44]. The physical interpretations of the variables of the model are presented in Figure 6.

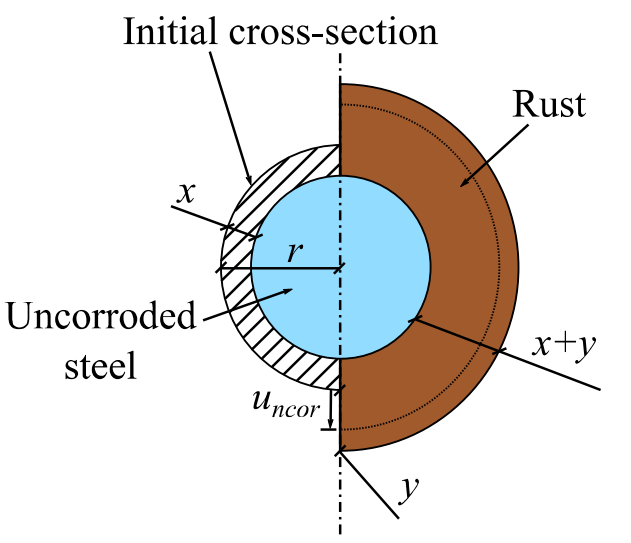

Corrosion penetration: $x$

Volume rust / volume steel: $\vartheta_{r s}$

Free increase of the radius: $y$

Real increase of the radius: $u_{n c o r}$

Figure 6. Physical interpretations of the variables in the corrosion model, modified from [26]. 


\subsubsection{FE model description}

3D NLFE analyses were performed using commercial software DIANA 9.5 [47]. The modelled beams had the same dimensions as the tested specimens accounting for the different geometrical specifications of each specimen. The exact positions of the reinforcement bars as well as the stirrups were taken into account in the development of each model by means of a detailed inspection of the specimen after testing; see [30] for more information. The symmetry of the test setup allowed for half of the beam to be considered in the model as shown in Figure 7. A special attention was given to the boundary conditions at the support around the suspension holes. On the top node of the suspension hole, boundary conditions were applied only allowing movement in the longitudinal direction. The other nodes at the suspension holes were eccentrically tied to the top node of the suspension hole, to avoid undesirable local failure, while allowing the rotation around the suspension hole. In the symmetry plane at the mid span, the nodal translations in the longitudinal direction were restrained.

Concrete and reinforcement bars were modelled using 3D tetrahedral elements (TE12L), and 2D interface elements (IF6L) were generated between the concrete and steel elements. The loading zone was modelled by means of a wooden board and steel plate using triangular-prism elements (TP18L) trying to reproduce testing conditions. The load was applied by means of displacement control regime applied on a master node at the top of the steel plate. All nodes at the upper face of the loading plate were forced to remain on a straight line. This was done using a tying which fixed a series of slave nodes along the steel plate to the loaded master node.

Concrete was modelled with a constitutive model based on non-linear fracture mechanics using a total strain based smeared-crack model with rotating crack approach [47]. Thorenfeldt compression function [48] was used to describe the behaviour of concrete in compression. The tensile behaviour was modelled using a stress-strain relation proposed by Hordijk [49] for tension softening, assuming the crack bandwidth to equal the element size. Thus, strain localization in tension was assumed to take place in single element rows; this was later verified to be a reasonable approximation of the localisation zone in the analyses. The reinforcing steel was modelled using an isotropic plasticity model with Von Mises yielding criterion including hardening. The material properties for concrete and steel used in the analysis are listed in Table 1 and Table 3 , respectively.
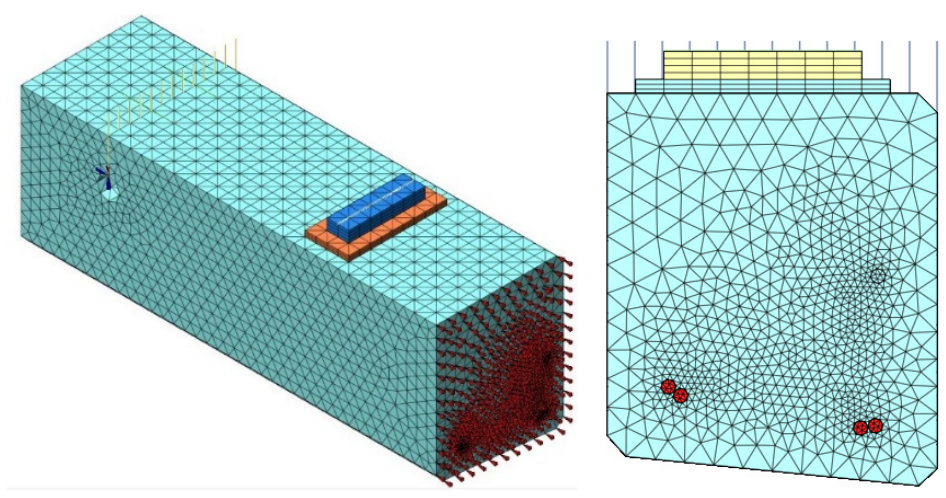

Figure 7. Overview of a FE model 
Incremental static analyses were carried out using a Newton-Raphson iterative scheme to solve the non-linear equilibrium equations. Each analysis was performed in three phases. First, corrosion was applied to the interface elements to generate splitting cracks and bond degradation; this was performed by applying time steps. It should be noted that even though the measured corrosion level varied between the different bars in one specimen, for the sake of simplicity, the average corrosion penetration was applied to all bars in the analyses of each specimen. In the second phase, the self-weight of the specimen was applied. In the third and final phase, the mechanical loading was applied in displacement steps.

\subsubsection{Results of Level IV analysis}

In Level IV analyses, all specimens failed in a splitting-induced pull-out failure mode, similar to that observed in the experiments. An example of results from one of the analyses (specimen M5) is shown in Figure 8. The crack pattern from the numerical analyses agreed well with the documented crack patterns in the experiments, in both the corrosion phase and mechanical loading phase. Figure 9 shows a comparison between the crack pattern in the corrosion phase from level IV analysis and experiment for specimen M5.

In all analyses, two shear cracks propagated in the shear span; this was similar to the crack patterns observed in the experiments. The distance from the end of the beam to the point where the outermost shear crack (crack \#2 in Figure 10) crossed the reinforcement was denoted available anchorage length which is marked in Figure 10. The available anchorage lengths in the analyses agreed rather well with the measured ones in the experiments; see Table 4.
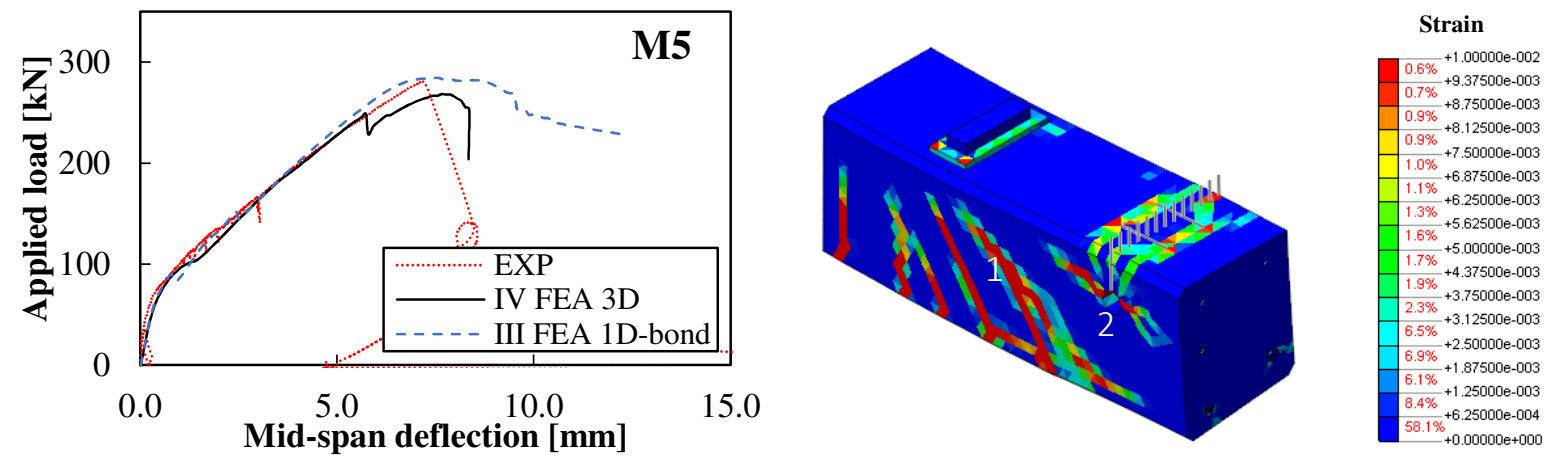

Figure 8. Specimen M5 (a) load-displacement from 3D NLFE analyses in levels IV and III (b) crack pattern at the failure load from level IV analysis shown in terms of the maximum principal strains.
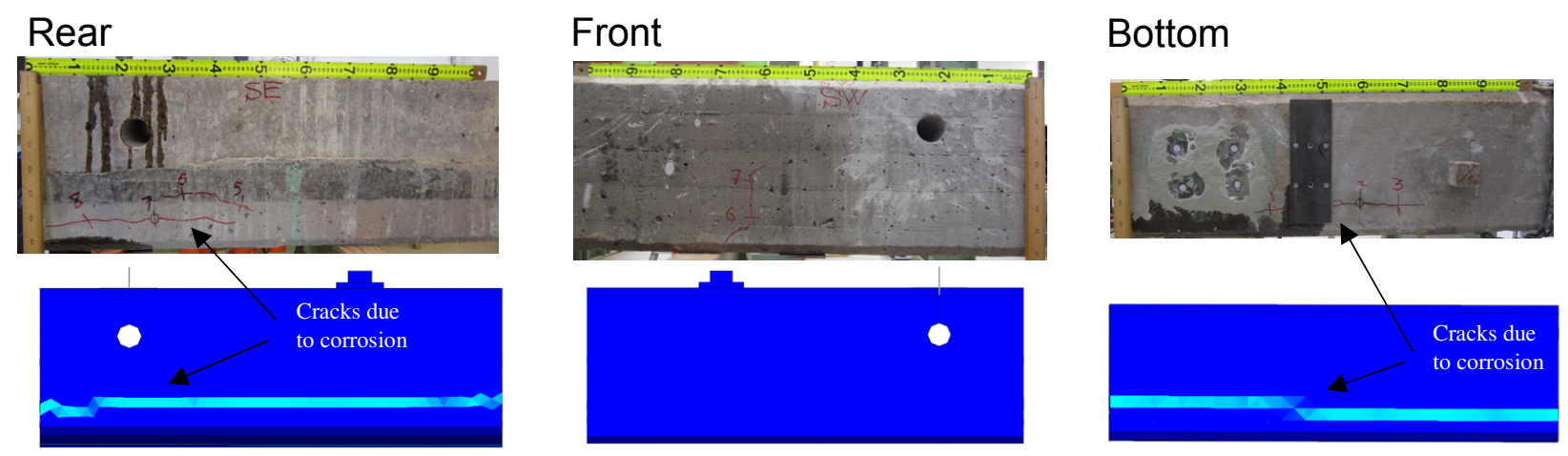

Figure 9. Comparison of the documented corrosion-induced splitting cover cracks with that from Level IV analysis in specimen M5 at an average corrosion level of 1.8\%. 

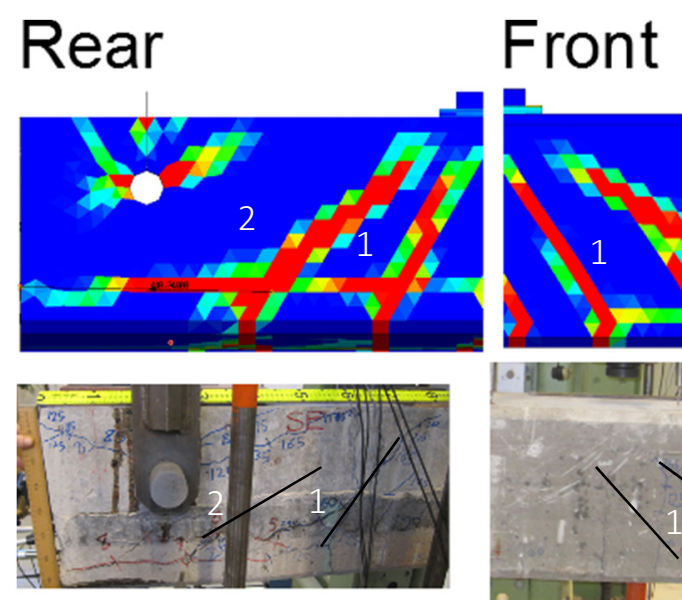

Figure 10. Comparison of crack patterns from Level IV analysis and experiment after mechanical loading on both front and rear sides of specimen M5.

In general, splitting cracks observed in the analyses propagated from the reinforcement bundles towards the surface with the smallest concrete cover. However, in some cases this did not agree with the experimental documentation of splitting cracks. This might have been caused by the fact that the average corrosion penetration was applied uniformly both around and along the reinforcement bars in the analyses. However, in reality the reinforcement bars were corroded with different patterns and to varying levels. In the analyses of the Highly damaged specimens, the splitting cracks propagated but the spalling of the concrete cover did not occur, as it had happened in reality.

Overall, the maximum load capacity was reasonably well described by Level IV analyses; for five of the six tests it only differed by less than $\pm 5 \%$ compared to experimental results; see Table 5. For the sixth specimen, H6, the analysis did not converge with the regular NewtonRaphson iteration used in the other analyses. Instead, Quasi-Newton BFGS was used and a converged solution was thereby obtained. However, in this analysis the maximum capacity was overestimated by about $20 \%$. Furthermore, the global stiffness of the beams was overestimated in the analyses of both Highly corroded specimens, H6 and H7, as well as in one of the Reference specimens, R4. This behaviour was probably due to pre-existing bending cracks, which had not been accounted for in the analyses. Overall, the end-slip behaviour was also reasonably well described by the analyses given the scatter expected for such tests; see Figure 11. In all tests and analyses, the slip of the bundles started at load levels well below the failure load; between 100 to $200 \mathrm{kN}$. After the maximum load, the end-slip continued to increase, in some cases beyond $2.0 \mathrm{~mm}$, with a ductile behaviour. This is an indication of splitting-induced pull-out failure mode in all analyses and experiments. Finally, it is worth noting that the analyses at this level were time consuming considering both the required computation time and the effort needed to handle possible convergence issues. 

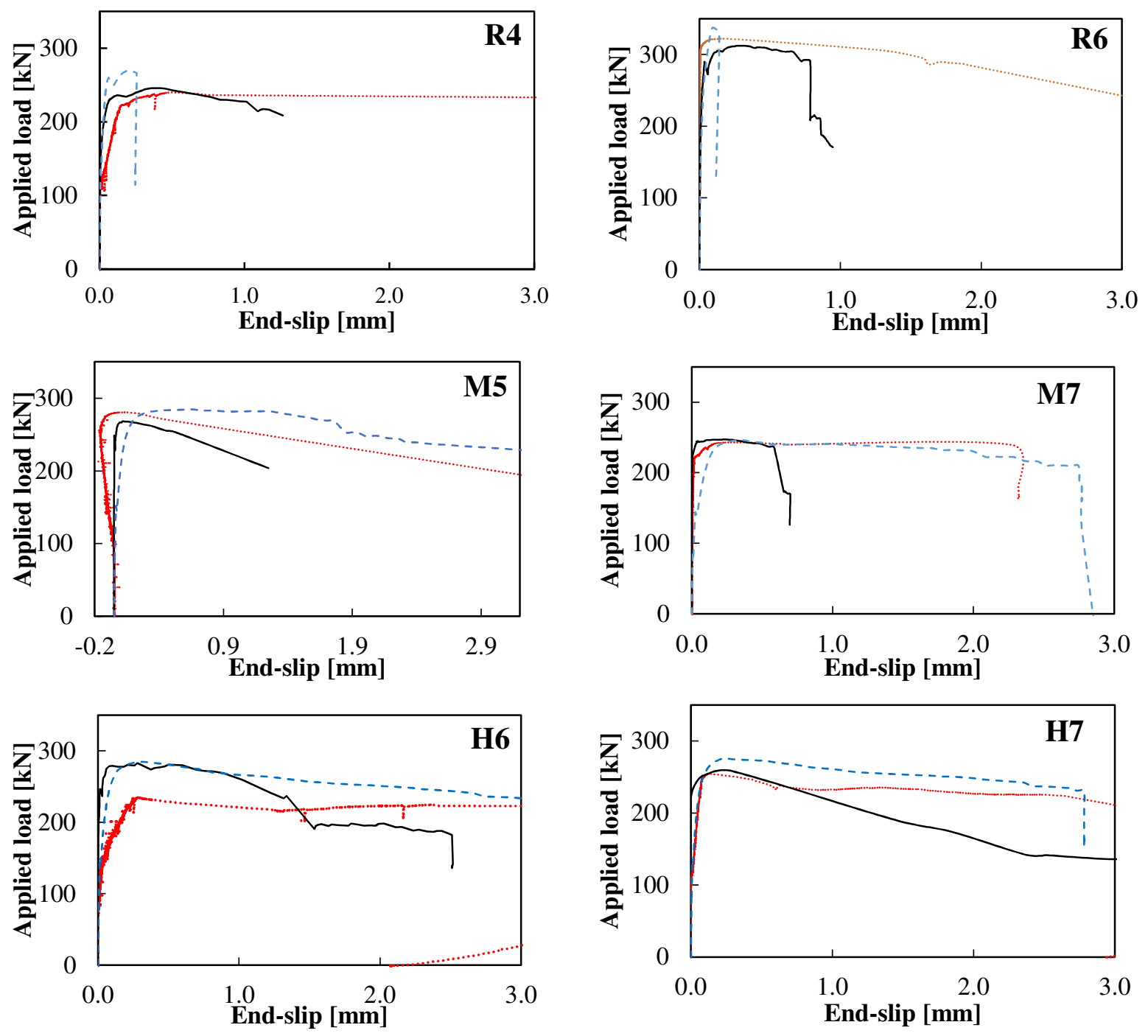

Figure 11. Comparison of the applied load versus free end-slip in Level IV and III analyses and experiments.

\subsection{Three-dimensional FE analysis with a pre-defined $1 D$ bond-slip relation between concrete and steel (Level III)}

\subsubsection{FE model description}

In Level III analysis, a more simplified approach to model the anchorage capacity of naturally corroded specimens was used. Similar finite element mesh as in Level IV analyses was adopted to enable a direct comparison of the results from Level III and IV analyses. Thus, the basis of each model was the same as described in Section 3.1.3. The following modifications were made to the model: (a) 2D interface elements between concrete and steel reinforcement bars were removed (b) the solid elements that in Level IV analyses constituted reinforcement bars were redefined to be concrete (c) steel bars were instead modelled by means of the bond-slip reinforcement approach defined in Diana 9.5 [47]. In this approach, bond-slip reinforcements not only add stiffness to the mother concrete elements, but also reinforcement bars are internally modeled as truss or beam elements, which are connected to the mother concrete elements by 
line interface elements. Hence, elastic or nonlinear bond-slip relation may be defined for the line interface elements in the bond-slip reinforcements [47].

\subsubsection{Pre-defined $1 D$ bond-slip relation and bundle consideration}

For uncorroded reinforcement, the 1D bond-slip relation used as input in Level III analysis was defined according to the local bond-slip relation in fib Model Code 1990 [33]. Following Model Code provisions, a choice between either "good" or "other" bond conditions has to be made. As there is not a clear distinction between these two cases, it was assumed that the bond between concrete and reinforcements was good enough before the corrosion took place; i.e. "good" bond conditions was assumed for the analyses. Furthermore, the 1D bond-slip relation was obtained from a linear interpolation between unconfined and confined cases according to Lundgren et al. [50], i.e. the two specific cases were computed as described in the fib Model Code 1990 and the final 1D bond-slip relation resulted from the interpolation. All required input data were chosen as described by Lundgren et al. [50].

For corroded reinforcement, the effect of corrosion on 1D bond-slip relation was taken into account, according to Lundgren et al. [50], in two steps:

a. The local bond- slip relation of corroded reinforcement is approximated by shifting the uncorroded curve in the slip direction. The local bond-stress slip curve for corroded reinforcement is then obtained as the minimum bond stress value of the original and the shifted curve. In other terms, the approximation means that corrosion exhausts the bond capacity in a similar manner as plastic slip. The principle is illustrated in Figure 12.

b. The change of failure mode, from pull-out to splitting failure as the result of corrosioninduced cracks, is accounted for by assuming that the remaining bond capacity depends only on the transverse reinforcement after corrosion-induced cracking. Before the cover is cracked, the cover also contributes to the capacity.

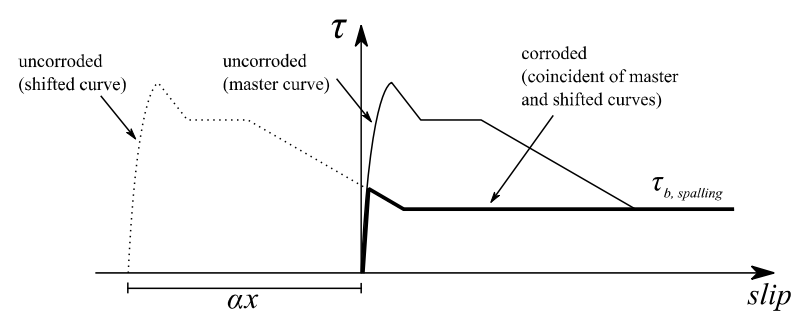

Figure 12. Scheme of a local bond-slip curve for 'good' bond conditions. The curve is an interpolation of confined and unconfined cases, modified from Lundgren et al. [50].

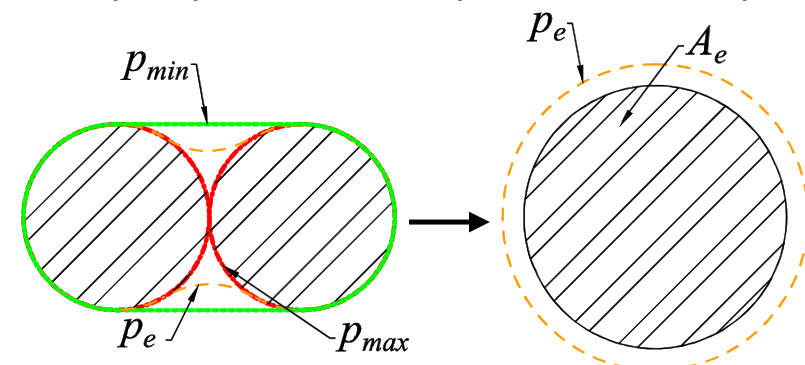

Figure 13. Scheme of the minimum, maximum and average perimeters and the equivalent area and perimeter for the bundled reinforcement bars. 
It is worth mentioning that corrosion was described by means of the equivalent corrosion penetration (uniform corrosion) which produced the same weight reduction as measured in the laboratory. Different hypotheses could be made for the consideration of bundled reinforcement bars. In this study, a circular bar with an equivalent area of two single bars, $A_{e}$, was used; i.e. the diameter of such a bar was used when calculating the cover-to-bar diameter ratio to estimate the splitting effects; see Figure 13b. Furthermore, the bonded perimeter of the bundle, $P_{e}$, was calculated as an average value of the upper bound, $P_{\max }$, and lower bound, $P_{\min }$, proposed by Jirsa et al. [51]; see Figure 13a. It should be noted that this perimeter can also affect the local bond-slip defined according to Lundgren et al. [50], as it influences the amount of transverse reinforcement that results in pull-out failure.

The main input parameters used to define the 1D bond-slip relation are provided in Table 1. Examples of resulting 1D bond-slip curves are shown in Figure 14; these curves were used as input in Level III analyses.

\subsubsection{Results of Level III analysis}

Level III analyses of all studied specimens resulted in anchorage failure; an example of loaddisplacement curve for specimen M5 is shown in Figure 8a. The maximum load capacity agreed reasonably well with the experimental results, even though a small overestimation was observed in all cases; see Table 5. In addition the beam stiffness was overestimated in the analyses of the uncorroded specimens, most likely because, just similar to Level IV analysis, the pre-existing damage to the specimens, such as bending cracks, was not directly accounted for in the models. In general, the end-slip behaviour agreed rather well with the experimental results; see Figure 11.

Figure 15b shows the crack pattern and remaining anchorage length for specimen M5. As can be seen, two shear cracks appeared along the shear span in the experiments (marked \#1 and \#2 in Figure 15a); whereas, just one shear crack was developed in Level III analysis. The same was observed for all corroded specimens. This behaviour resulted in larger available anchorage lengths compared to the experiments for all corroded specimens; see Table 4. Accordingly, the load capacity was slightly higher in the analyses than in the experiments, as the anchorage capacity is related to the available anchorage length. One probable reason for this mismatch crack pattern is that Level III analysis could not directly describe the splitting stresses and corrosion cracking; in the tested beams splitting cracks took place, and they connected with the second shear crack towards the end of the bars. To describe this interaction, the pre-defined bond-slip relation was too simplified and a more sophisticated modelling including the splitting stresses of both corrosion and bond, as in Level IV analysis, would have been needed.

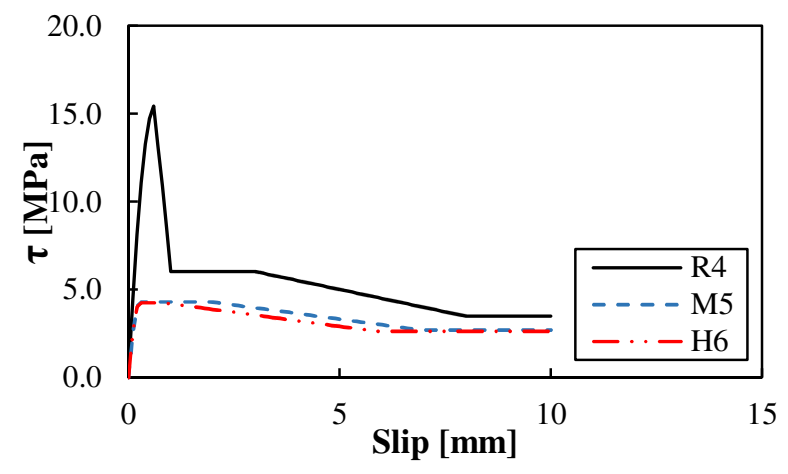

Figure 14. 1D bond-slip relation for three specimens used in Level III analysis. 
(a)
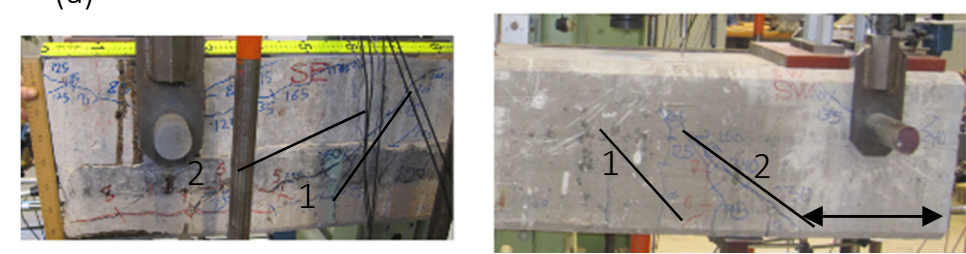

$431 \mathrm{~mm}$

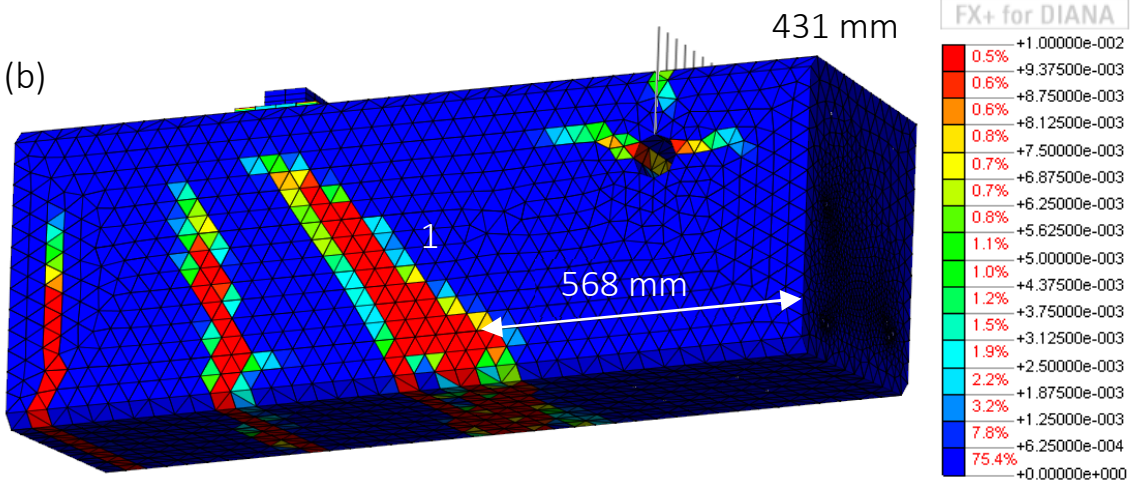

Figure 15 Comparison of the crack pattern and the available anchorage length from Level III analysis with experimental documentation for specimen M5: (a) front and rear sides of the beam, (b) $3 D$ view of the crack pattern.

On the other hand, a second shear crack was generated in the uncorroded specimens in Level III analysis. The measured anchorage length was then closer to the experimental ones. Consequently, the estimation of the anchorage capacity was closer to the experimental results. It is worth noting that the utilized 1D bond-slip curves were stronger for the uncorroded specimens, which allowed for the actual development of the second shear cracks, as well as showing better agreement with the tests.

Table 4. Measured available anchorage length from Level IV and III analyses and the experiments, average of front and rear sides.

\begin{tabular}{|c|c|c|c|c|c|}
\hline \multirow[b]{2}{*}{ Specimen } & \multicolumn{5}{|c|}{ Available anchorage length [mm] } \\
\hline & Level IV & $\begin{array}{c}\text { Ratio } \\
\text { IV/EXP }\end{array}$ & Level III & $\begin{array}{l}\text { Ratio } \\
\text { III/EXP }\end{array}$ & EXP \\
\hline $\mathrm{R} 4$ & 270 & 1.05 & 127 & 0.49 & 257 \\
\hline R6 & 405 & 0.93 & 340 & 0.78 & 437 \\
\hline M5 & 418 & 0.97 & 561 & 1.30 & 431 \\
\hline M7 & 318 & 1.01 & 439 & 1.40 & 314 \\
\hline H6 & 407 & 0.95 & 472 & 1.11 & 427 \\
\hline $\mathrm{H} 7$ & 291 & 0.92 & 430 & 1.37 & 315 \\
\hline
\end{tabular}




\section{$3.31 D$ bond-slip model and a given available anchorage length (Level II)}

For the analyses at Level II, the same 1D bond-slip relations as in Section 3.2.2 and the experimentally measured available anchorage length were used. The anchorage capacity was obtained by numerically solving the 1D differential equation along the anchorage length combined with a simple structural model to calculate the capacity of the specimen, both of which are shortly described in the following sections.

\subsubsection{D differential equation along the anchorage length}

In Level II analyses, the differential equation expressing equilibrium conditions along the bundled reinforcement was derived as:

$2 \cdot \frac{\pi \cdot \emptyset^{2}}{4} \cdot \frac{d \sigma_{s}}{d x}-p_{e} \tau=0$

where $\phi$ is the reinforcement diameter of a single bar of the bundle, $\sigma_{s}$ is the stress in the steel reinforcement, $p_{e}$ is the bonded perimeter of the bundle shown in Figure 13 and $\tau$ is the bond stress. The stress in the reinforcement was assumed to be in the elastic range according to eq. (3).

$\sigma_{s}=E_{s} \cdot \varepsilon_{s}, \varepsilon_{s}=\frac{d u}{d x}$

where $E_{s}$ is elastic modulus of the rebar, $\varepsilon_{s}$ is the strain and $u$ is the displacement of the reinforcement. The deformation of the surrounding concrete was assumed negligible; therefore, the displacement of the reinforcement is equal to the slip. Furthermore, to solve the equilibrium equation stated in eq. (2), boundary conditions based on the pull-out of the bundled reinforcement having a length $L$ and a prescribed displacement $u_{L}$ were defined as described in eq. (4).

$\sigma_{s}(0)=0, u(L)=u_{L}$

The pull-out responses were computed using a differential equation solver in MATLAB software. Further details regarding the development and implementation of the Level II analysis can be found in Lundgren et al. [50].

\subsubsection{Structural model}

After solving the differential equation in eq. (2), the tensile force, $F_{t}$, at the end of the remaining available anchorage length was obtained by multiplying the stress in the steel reinforcement at the active end of the bar by the cross-sectional area of the steel. To estimate the load applied to the tested beam, $P$, from the anchored force $F_{t}$, the same structural model as presented by Lundgren et al. [32] was used here; see Figure 16.

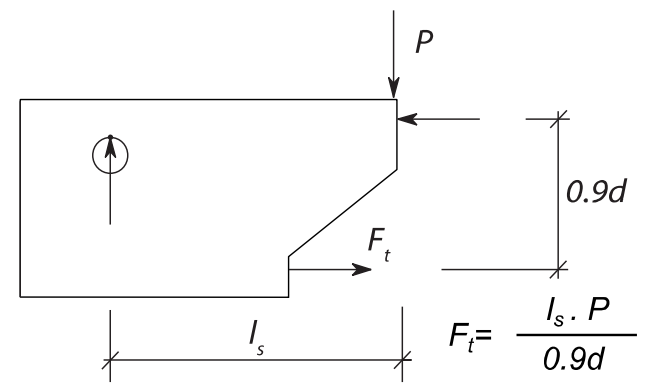

Figure 16. Structural model to relate the applied load with the anchored tensile force in the reinforcement, modified from Lundgren et al. [32]. 


\subsubsection{Results of Level II analysis}

The analyses at Level II of the corroded specimens resulted in anchorage failure and yielded reasonable estimations of the maximum capacity; see Table 5. It should however be noted that the difference between the calculated and the measured capacity varied from $-46 \%$ to $+4 \%$, much more than the corresponding difference with Level III and IV analyses. As far as corroded specimens were concerned, all but one of the analyses were on the safe side.

The analyses of the uncorroded specimens did not result in anchorage failure as the tests did; instead, they failed due to yielding of reinforcement. Thus, it is concluded that the $1 \mathrm{D}$ bondslip curves proposed in the fib Model Code 1990 [33] overestimated the bond capacity for uncorroded bundled reinforcement. Furthermore, the applied load versus the end-slip in all analyses showed a weaker behaviour than the measured results; examples are shown in Figure 17.
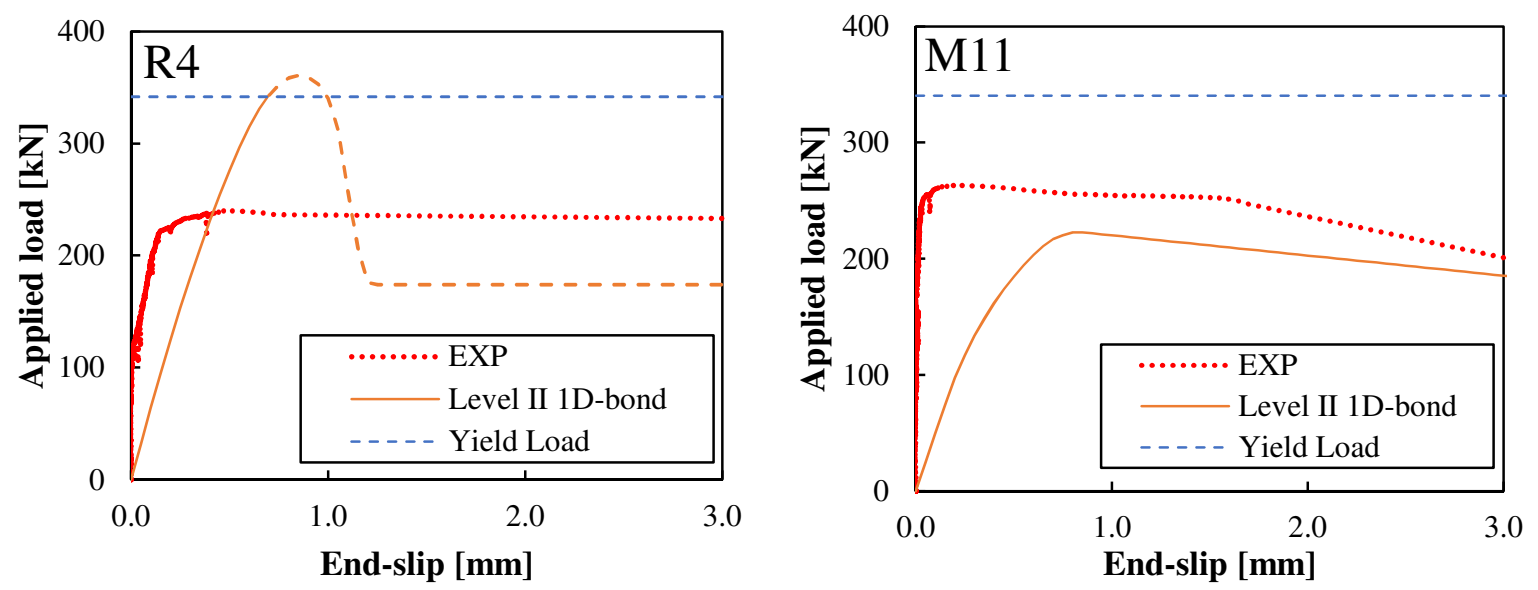

Figure 17. Applied load versus end-slip for specimens $R 4$ and M11 compared with experimental data.

\subsection{Simple approach for engineering practice (Level I)}

The Level I analysis is a simplified method to predict the remaining anchorage capacity in corroded RC structures. The residual bond capacity from 1D bond-slip model, employed in Level II analysis, is used together with an assumption of a constant bond stress along the anchorage length. Thus, the remaining anchorage capacity is calculated as

$$
F_{a}=\tau_{b, \text { spalling }} \cdot p_{e} \cdot l_{a}
$$

where $l_{a}$, is the measured available anchorage length, $p_{e}$ is the equivalent perimeter of the bundle defined in Figure 13, and $\tau_{b \text {,spalling }}$ is the residual bond capacity for 'good' bond conditions; see Figure 12. The residual bond capacity can be calculated as

$$
\tau_{b, \text { spalling }}=\left(0.3+\left(\frac{0.7 \cdot f_{s w}}{p_{e} \cdot \tau_{\max , \text { conf }}}\right)\left(\frac{A_{s w}}{s}\right)\right) \cdot \sqrt{f_{c}},
$$

where $f_{s w}$ and $A_{s w}$ are the yield strength and cross-sectional area of the stirrups, and $s$ is the stirrup spacing. This equation is equivalent to that provided by [19], with a minor modification to be valid for bundles. The maximum bond strength, $\tau_{\max , \text { conf }}$, for confined concrete was calculated as given in fib Model Code 1990 [33]. 


$$
\tau_{\max , \mathrm{conf}}=2.5 \sqrt{f_{c}}
$$

The same structural model as in Level II analyses was used to link the anchorage capacity to the applied load; see Figure 16.

The results from this simple approach are provided in Table 5. As can be seen, the calculated capacity was largely underestimated compared to experimental results, as well as when compared with the other three modelling levels. However, it should be noted that this method required very little time; it was meant to be a quick and easy way of making an initial check as to whether the anchorage capacity could be sufficient. As such, the method is trustworthy, as it yielded results on the safe side. If sufficient capacity cannot be shown with an analysis on this level, it may worthwhile to make a more detailed analysis to possibly show a higher capacity.

\section{Discussion of the results}

\subsection{General discussion}

The anchorage capacity of six naturally corroded specimens with varying degrees of corrosion damage were modelled with the help of four different modelling approaches. The two FE approaches are compared with experimental data in Figure 18. In the Level IV analysis, the maximum load applied showed the least deviations from experimental data. The results of the Level III analysis were also reasonable when compared to experimental data and Level IV results; however, the capacity of the specimens was overestimated in all cases. The results of both Level IV and II analyses in the Reference and Medium damaged groups were close enough to experimental data in terms of the maximum mid-span deflection, while both analyses evidenced slightly large deviations in the Highly damaged category; see Figure 18.

Table 5. Comparison of maximum applied load among four levels of analysis and experiments.

\begin{tabular}{|c|c|c|c|c|c|c|c|c|c|}
\hline \multirow[b]{2}{*}{ Specimen } & \multicolumn{2}{|c|}{ Level IV } & \multicolumn{2}{|c|}{ Level III } & \multicolumn{2}{|c|}{ Level II } & \multicolumn{2}{|c|}{ Level I } & EXP \\
\hline & $\begin{array}{l}\text { Load } \\
{[\mathrm{kN}]}\end{array}$ & $\begin{array}{l}\text { Load } \\
\text { ratio } \\
\text { IV/EXP } \\
{[-]}\end{array}$ & $\begin{array}{l}\text { Load } \\
{[\mathrm{kN}]}\end{array}$ & $\begin{array}{l}\text { Load } \\
\text { ratio } \\
\text { III/EXP } \\
{[-]}\end{array}$ & Load $[\mathrm{kN}]$ & $\begin{array}{l}\text { Load } \\
\text { ratio } \\
\text { II/EXP } \\
{[-]}\end{array}$ & $\begin{array}{l}\text { Load } \\
{[\mathrm{kN}]}\end{array}$ & $\begin{array}{l}\text { Load } \\
\text { ratio } \\
\text { I/EXP } \\
{[-]}\end{array}$ & $\begin{array}{l}\text { Load } \\
{[\mathrm{kN}]}\end{array}$ \\
\hline R4 & 245.8 & 1.02 & 269.4 & 1.12 & $341.9 *$ & 1.42 & 77.5 & 0.32 & 240.1 \\
\hline R6 & 312.1 & 0.97 & 337.5 & 1.05 & $342.4 *$ & 1.06 & 130.8 & 0.41 & 322.0 \\
\hline M4 & - & - & - & - & 199.6 & 0.76 & 126.8 & 0.48 & 264.2 \\
\hline M5 & 268.3 & 0.96 & 284.7 & 1.01 & 195.7 & 0.70 & 122.2 & 0.43 & 280.9 \\
\hline M7 & 247.1 & 1.02 & 246.6 & 1.01 & 141.0 & 0.58 & 87.7 & 0.36 & 243.3 \\
\hline M8 & - & - & - & - & 248.5 & 0.76 & 104.0 & 0.32 & 326.8 \\
\hline M9 & - & - & - & - & 243.3 & 1.04 & 96.2 & 0.41 & 234.1 \\
\hline M10 & - & - & - & - & 153.3 & 0.58 & 96.3 & 0.36 & 264.9 \\
\hline M11 & - & - & - & - & 222.7 & 0.85 & 143.1 & 0.54 & 263.2 \\
\hline M12 & - & - & - & - & 222.0 & 0.85 & 137.6 & 0.53 & 260.0 \\
\hline H5 & - & - & - & - & 221.6 & 0.72 & 141.3 & 0.46 & 307.6 \\
\hline H6 & 282.8 & 1.20 & 285.0 & 1.21 & 189.7 & 0.81 & 118.6 & 0.50 & 234.9 \\
\hline $\mathrm{H} 7$ & 258.6 & 1.01 & 275.7 & 1.08 & 138.8 & 0.54 & 86.5 & 0.34 & 255.3 \\
\hline
\end{tabular}

*The value given in the table is the yield capacity. 
The results of the maximum applied load for all four approaches and experimental measured loads are compiled in Table 5 and Figure 19. As expected, the accuracy of the results compared with the measured experimental data increased from a simple engineering approach to the more advanced FE modelling. It should be mentioned that in Levels I and II analyses, the available anchorage length was an input parameter, which is not always easy to measure or estimate.

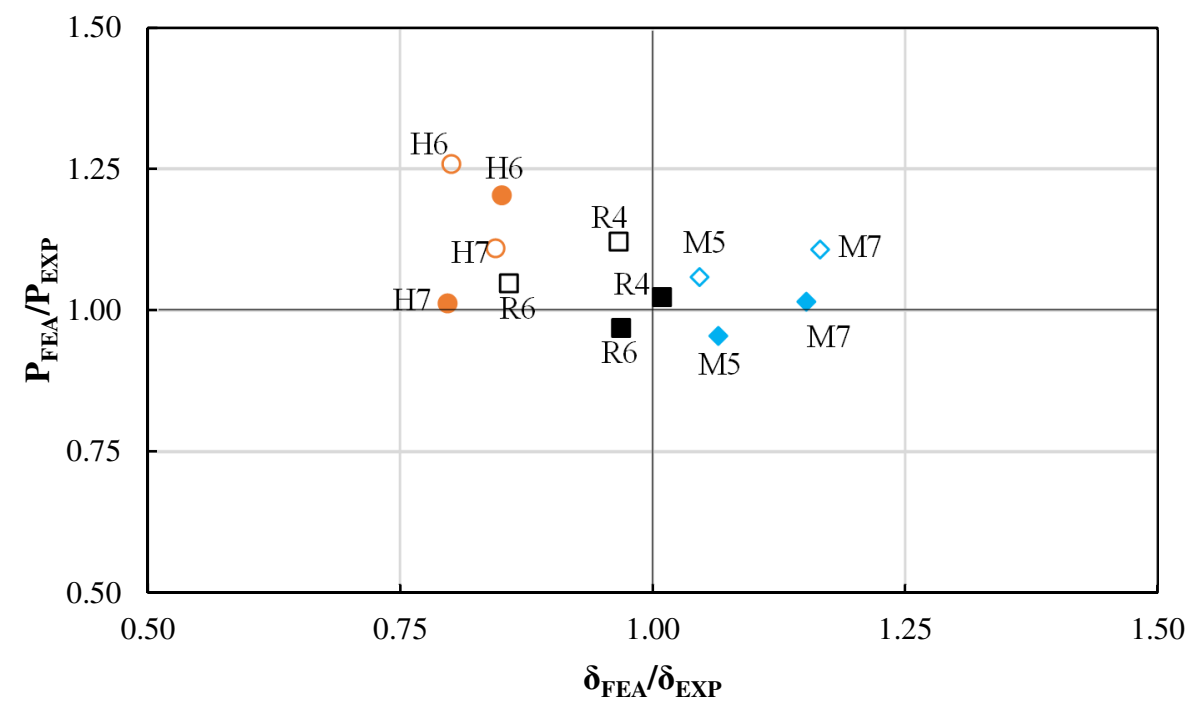

Figure 18. Comparison of results from experiments and numerical analyses in terms of maximum load and the mid-span displacement reached at peak loads. The results of Levels IV and III are shown with filled in and empty markers, respectively.

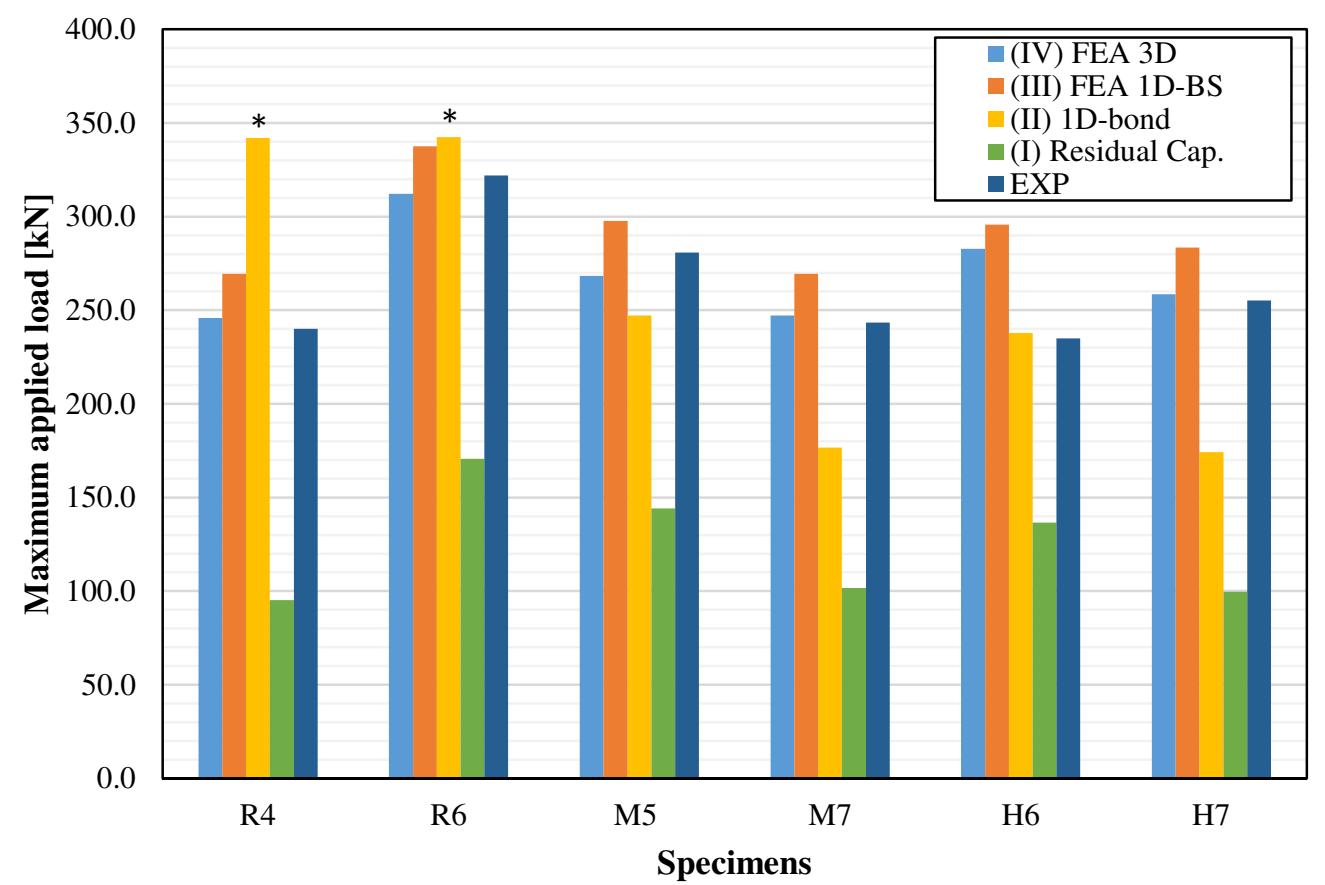

Figure 19. Comparison of the results from experiments and four analysis approaches in terms of maximum load. The capacity of the specimens marked with an asterisk was limited by yielding of the reinforcement in Level II analysis. 
The corrosion-induced cracks could only be simulated using the most advanced analysis, Level IV. These corrosion effects had to be taken indirectly into account in other approaches, which led to less agreement in the crack pattern for Level III analysis, or in conservative anchorage capacities for Level II analysis. The crack patterns obtained in Level IV analysis were accordingly in better agreement with the experimentally documentation ones. In general, the analyses at Levels IV and III required more input parameters. The modelling procedure and analysis at Level IV were more time-consuming than those at Level III. In the analyses at Level IV, the external pressure from supports and splitting effects due to the reinforcement slip were also directly taken into account. Thus, the analysis results at Level IV were closer to the real conditions of the experiments than at Level III. The analyses at Levels II and I were quite time efficient. However, the results were not as reliable as those in the two aforementioned FE approaches. Thus, the analyses at Levels II and I are recommended for preliminary evaluations of the residual bond capacity for engineering purposes. In Table 6, a summary of approximate computation time and outcome of the analyses of the four different levels is provided. The preparation and model development time are not included.

\subsection{Discussion of the chosen bundle assumption}

In this section, the method used to consider bundles is compared with three other potential methods: (1) one circular bar with the equivalent area of two single bars, $A_{e}$, and the upper bound of the perimeter, $A_{\max }$, (2) one circular bar with the equivalent area of two single bars, $A_{e}$, and the lower bound of the perimeter, $A_{\min }$, and (3) two single bars; see Figure 13.

In Figure 20, the local bond-slip relations of an uncorroded specimen according to fib Model Code 1990 [33] are shown for the different methods of bundle consideration. As expected, bond stresses highly depend on the ratio between concrete cover and bar diameter. Thus, the method with two single bars resulted in a significantly higher concrete cover/bar diameter ratio and consequently much higher local bond strength. On the other hand, the choice of one bar with the different perimeters did not largely affect the local bond-slip relation.

When looking at the results in Figure 20, the single bar assumption was considered to give too high residual bond capacity; thus the additional splitting stresses caused by bundled bars were considered to be underestimated when using the single bar assumption. Accordingly, the approach of one circular bar with the equivalent area of the two single bars, $A_{e}$, together with the average of the upper and lower bounds of the perimeter, $A_{e}$, was chosen in this study.

Table 6. Approximate computation time and outcome of the analyses

\begin{tabular}{|c|c|c|c|c|c|c|}
\hline \multirow{2}{*}{$\begin{array}{c}\text { Analysis } \\
\text { level }\end{array}$} & \multirow{2}{*}{$\begin{array}{l}\text { Analysis } \\
\text { time }\end{array}$} & \multirow{2}{*}{$\begin{array}{c}\text { Load } \\
\text { capacity }\end{array}$} & \multirow{2}{*}{$\begin{array}{l}\text { End-slip } \\
\text { behaviour }\end{array}$} & \multicolumn{2}{|c|}{ Crack pattern } & \multirow{2}{*}{$\begin{array}{c}\text { Effect of } \\
\text { transverse } \\
\text { pressure }\end{array}$} \\
\hline & & & & $\begin{array}{c}\text { Induced by } \\
\text { mechanical loading }\end{array}$ & $\begin{array}{l}\text { Corrosion/slip } \\
\text { induced }\end{array}$ & \\
\hline IV & $12-14 \mathrm{hrs}$ & $\checkmark$ & $\checkmark$ & $\checkmark$ & $\checkmark$ & $\checkmark$ \\
\hline III & $2-3 \mathrm{hrs}$ & $\checkmark$ & $\checkmark$ & $\checkmark$ & & \\
\hline II & $2-3$ mins & $\checkmark$ & $\checkmark$ & & & \\
\hline I & Few sec. & $\checkmark$ & & & & \\
\hline
\end{tabular}




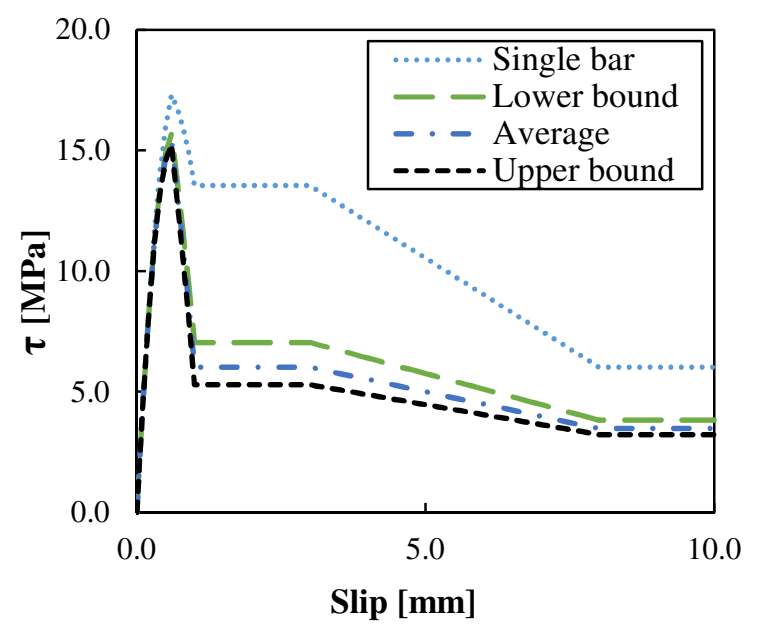

Figure 20. Comparison of the analytical model taking different assumptions into account for the bundled rebar (specimen $R 4$ ).

\section{Conclusions and outlook}

The paper has presented and described the scope of four different approaches analysing the anchorage behaviour of corroded RC structures. The following conclusions are drawn from this study:

- The models on different levels were for the first time compared with each other and to the results of naturally corroded specimens. Thereby, the knowledge gained from advanced modelling is brought to engineering practice.

- The 3D NLFE analyses including bond and corrosion models, Level IV analysis, yielded results that were mostly consistent with the observations in the experiments in terms of remaining anchorage capacity and crack patterns. However, these analyses were computationally expensive considering both the analysis time and the effort necessary to handle potential convergence issues.

- The 3D NLFE analyses considering 1D bond-slip relations, Level III analysis, described the overall structural behaviour reasonably well, although there was some overestimation of the capacity. The use of simple bond-slip relations between concrete and steel in complex FE analyses was useful and a good approximation of true behaviour could be obtained relatively quickly. However, this modelling technique could not take the splitting action into account; this was probably the reason for the deviation in the crack pattern, e.g., the second shear crack did not propagate in these analyses, resulting in longer available anchorage lengths and an overestimation of the capacities.

- In Level II analyses where the bond-slip relation was used together with a measured available anchorage length, the anchorage capacity was obtained by numerically solving the one-dimensional differential equation along the reinforcement. This approach was useful for the estimation of the anchorage capacity in damaged specimens. However, it led to an overestimation of the capacity for the undamaged beams. 
- The simplified engineering approach, Level I analysis, estimated the capacity by only considering the residual bond strength. The capacity was underestimated in all categories, indicating that this level of analysis is safe to use in practice. If sufficient capacity cannot be shown with an analysis on this level, it may be worthwhile to make a more detailed analysis to potentially show a higher capacity.

- Levels I and II approaches were the fastest and most efficient analyses. However, they were strongly dependent upon available data, such as available anchorage length, which might prove difficult to obtain.

\section{Acknowledgements}

This work was undertaken at Chalmers University of Technology, Division of Structural Engineering, Concrete Structures. The authors would like to acknowledge the funding from the Swedish Transport Administration (Trafikverket).

\section{References}

[1] I. Fernandez, M. F. Herrador, A. R. Marí, and J. M. Bairán, "Structural effects of steel reinforcement corrosion on statically indeterminate reinforced concrete members," Mater. Struct., vol. 49, no. 12, pp. 4959-4973, Dec. 2016.

[2] J. Cairns and S. Millard, "Reinforcement corrosion and its effect on residual strength of concrete structures," in Proceeding of the 8th International Conference on Structure Faults and Repair, 1999.

[3] CEB-fib, "Bond of reinforcement in concrete. Bulletin 10," Lausanne, Swetzerland, 2000.

[4] A. a. Almusallam, "Effect of degree of corrosion on the properties of reinforcing steel bars," Constr. Build. Mater., vol. 15, no. 8, pp. 361-368, Dec. 2001.

[5] Y. G. Du, L. A. Clark, and A. H. C. Chan, "Effect of corrosion on ductility of reinforcing bars," Mag. Concr. Res., vol. 57, no. 7, pp. 407-419, 2005.

[6] I. Fernandez, J. M. Bairán, and A. R. Marí, "Corrosion effects on the mechanical properties of reinforcing steel bars. Fatigue and $\sigma-\varepsilon$ behavior," Constr. Build. Mater., vol. 101, pp. 772-783, Dec. 2015.

[7] I. Fernandez, J. M. Bairán, and A. R. Marí, "3D FEM model development from 3D optical measurement technique applied to corroded steel bars," Constr. Build. Mater., vol. 124, pp. 519-532, 2016.

[8] I. Fernandez, J. M. Birán, and A. R. Marí, "Mechanical model to evaluate steel reinforcement corrosion effects on $\sigma-\varepsilon$ and fatigue curves. Experimental calibration and validation," Eng. Struct., 2016.

[9] G. J. Al-Sulaimani, M. Kaleemullah, I. A. Basunbul, and Rasheeduzzafar, "Influence of corrosion and cracking on bond behavior and strength of reinforced concrete members," $A C I$ Struct. J., vol. 87, no. 87, pp. 220-231, 1990. 
[10] V. H. Dang and R. François, "Influence of long-term corrosion in chloride environment on mechanical behaviour of RC beam," Eng. Struct., vol. 48, pp. 558-568, Mar. 2013.

[11] D. V. Val, M. G. Stewart, and R. E. Melchers, "Effect of reinforcement corrosion on reliability of highway bridges," Eng. Struct., vol. 20, no. 11, pp. 1010-1019, Nov. 1998.

[12] I. Sæther, "Structural behaviour of deteriorated and retrofitted concrete structures," Norwegian University of Science and Technology, Trondheim, Norway, 2010.

[13] M. Tahershamsi, I. Fernandez, K. Lundgren, and K. Zandi Hanjari, "Investigating Correlations between Crack Width, Corrosion Level and Anchorage Capacity," Struct. Infrastruct. Eng., vol. 2479, no. January, pp. 1-14, 2016.

[14] R. Tepfers, "A Theory of Bond Applied to Overlapped Tensile Reinforcement Splices for Deformed Bars.," Chalmer University, Goteborg, 1972.

[15] P. E. Regan and I. L. Kennedy Reid, "Assessment of Concrete Structures Affected by Delamination - 2," Stud. Res. - Annu. Rev. Struct. Concr., vol. 29, no. 1, pp. 245-275, 2009.

[16] I. Sæther, "Bond deterioration of corroded steel bars in concrete," Struct. Infrastruct. Eng., vol. 7, no. 6, pp. 415-429, 2011.

[17] K. Zandi Hanjari, D. Coronelli, and K. Lundgren, "Bond capacity of severely corroded bars with corroded stirrups," Mag. Concr. Res., vol. 63, no. 12, pp. 953-968, 2011.

[18] D. Coronelli, K. Z. Hanjari, and K. Lundgren, "Severely Corroded RC with Cover Cracking," J. Struct. Eng., vol. 139, no. 2, pp. 221-232, 2013.

[19] K. Zandi, "Corrosion-induced cover spalling and anchorage capacity," Struct. Infrastruct. Eng., no. February 2015, pp. 1-18, 2015.

[20] D. Law, Y. Du, and J. Cairns, "Structural performance of corrosion-damaged concrete beams," Mag. Concr. Res., vol. 60, no. 5, pp. 359-370, Jan. 2008.

[21] D. Coronelli, "Corrosion cracking and bond strength modeling for corroded bars in reinforced concrete," ACI Struct. J., vol. 99, pp. 267-276, 2002.

[22] X. Wang and X. Liu, "Bond strength modeling for corroded reinforcement in reinforced concrete," Struct. Eng. Mech., vol. 17, no. 6, pp. 863-878, 2004.

[23] M. Berra, A. Castellani, D. Coronelli, S. Zanni, and G. Zhang, "Steel-concrete bond deterioration due to corrosion: finite-element analysis for different confinement levels," Mag. Concr. Res., vol. 55, no. 3, pp. 237-247, Jun. 2003.

[24] H. S. Lee, T. Noguchi, and F. Tomosawa, "Evaluation of the bond properties between concrete and reinforcement as a function of the degree of reinforcement corrosion," Cem. Concr. Res., vol. 32, no. 8, pp. 1313-1318, 2002.

[25] K. Bhargava, A. K. Ghosh, Y. Mori, and S. Ramanujam, "Suggested Empirical Models for Corrosion-Induced Bond,” J. Struct. Eng., vol. 134, no. 2, pp. 221-230, 2008.

[26] K. Lundgren, "Bond between ribbed bars and concrete. Part 2: The effect of corrosion," Mag. Concr. Res., vol. 57, no. 7, pp. 383-395, 2005. 
[27] F. Biondini and M. Vergani, "Deteriorating beam finite element for nonlinear analysis of concrete structures under corrosion," Struct. Infrastruct. Eng., vol. 11, no. 4, pp. 519-532, 2014.

[28] M. Saifullah and L. A. Clark, "Effect of Corrosion Rate on the Bond Strength of Corroded Reinforcement," in Corrosion and Corrosion Protection of Steel in Concrete, 1994, vol. I, pp. 591-602.

[29] S. A. Austin, R. Lyons, and M. J. Ing, "Electrochemical behavior of steel-reinforced concrete during accelerated corrosion testing," Corrosion, vol. 60, no. 2, pp. 203-212, 2004.

[30] M. Tahershamsi, K. Zandi, K. Lundgren, and M. Plos, "Anchorage of naturally corroded bars in reinforced concrete structures," Mag. Concr. Res., vol. 66, no. 14, pp. 729-744, Jul. 2014.

[31] F. Berg and D. Johansson, "Design of Test Set-up using FEM Pilot Tests on Anchorage of Naturally Corroded Reinforcement," Master Thesis, Chalmers University of Technology, 2011.

[32] K. Lundgren, M. Tahershamsi, K. Zandi, and M. Plos, "Tests on anchorage of naturally corroded reinforcement in concrete," Mater. Struct., vol. 48, no. 7, pp. 2009-2022, Mar. 2015.

[33] fib Model Code, “CEB-FIP Model Code 1990 Design Code,” Lausanne, Swetzerland, 1990.

[34] M. J. Setzer et al., "Test methods of frost resistance of concrete: CIF-Test: Capillary suction, internal damage and freeze thaw test-Reference method and alternative methods A and B," Mater. Struct., vol. 37, no. December, pp. 743-753, 2004.

[35] T. C. Membership, C. Prof, M. J. Setzer, S. D. J. Janssen, M. R. Auberg, and D. H. Bager, "RILEM TC 176-IDC: 'Internal damage of concrete due to frost action,"” vol. 37, no. December, pp. 740-742, 2004.

[36] K. Z. Hanjari, P. Utgenannt, and K. Lundgren, "Experimental study of the material and bond properties of frost-damaged concrete," Cem. Concr. Res., vol. 41, no. 3, pp. 244-254, 2011.

[37] K. Z. Hanjari, P. Utgenannt, K. Lundgren, K. Zandi Hanjari, P. Utgenannt, and K. Lundgren, "Experimental study of the material and bond properties of frost-damaged concrete," Cem. Concr. Res., vol. 41, no. 3, pp. 244-254, Mar. 2011.

[38] M. Hassanzadeh and G. Fagerlund, "Residual strength of the frost-damaged reinforced concrete beams," III Eur. Conf. Comput. ..., no. June, p. 2006, 2006.

[39] K. Z. Hanjari, P. Kettil, and K. Lundgren, "Modelling the structural behaviour of frostdamaged reinforced concrete structures," Struct. Infrastruct. Eng., vol. 9, no. 5, pp. 416-431, 2013.

[40] Fib Model Code, Model Code 2010, Volume 1, vol. 1, no. March. International Federation for Structural Concrete, Lausanne, Switzerland, 2010.

[41] ASTM Standard G1, "Standard practice for preparing, cleaning, and evaluating corrosion test specimens.” 2011.

[42] K. Lundgren, "Bond between ribbed bars and concrete. Part 1: Modified model," Mag. Concr. Res., vol. 57, no. 7, pp. 371-382, Sep. 2005.

[43] K. Lundgren and K. Gylltoft, "A model for the bond between concrete and reinforcement," 
Mag. Concr. Res., no. 1, pp. 53-63, 2000.

[44] K. Lundgren, "Effect of corrosion on the bond between steel and concrete: an overview," Mag. Concr. Res., vol. 59, no. 6, pp. 447-461, Jan. 2007.

[45] K. Lundgren, "Modelling the effect of corrosion on bond in reinforced concrete," Mag. Concr. Res., vol. 54, no. 3, pp. 165-173, 2002.

[46] A. Jansson, I. Lofgren, K. Lundgren, and K. Gylltoft, "Bond of reinforcement in selfcompacting steel-fibre-reinforced concrete," Mag. Concr. Res., vol. 64, no. 7, pp. 617-630, Jul. 2012.

[47] Diana, "DIANA Finite Element Analysis, User's Manual, release 9.5," Delft, Netherlands, 2014.

[48] E. Thorenfeldt, A. Tomaszewicz, and J. J. Jensen, "Mechanical Properties of High-Strength Concrete and Applications in Design," in Concference on Utilization of High-Strength Concrete, 1987.

[49] D. A. Hordijk, "Local Approach to Fatigue of Concrete," Delft University of Technology, Delft, The Netherlands, 1991.

[50] K. Lundgren, P. Kettil, K. Z. Hanjari, H. Schlune, and A. S. S. Roman, "Analytical model for the bond-slip behaviour of corroded ribbed reinforcement," Struct. Infrastruct. Eng., vol. 8, no. 2, pp. 157-169, Feb. 2012.

[51] J. O. Jirsa, W. Chen, D. B. Grant, and R. Elizondo, "Development of Bundled Reinforcing Steel.pdf," Texas, USA, 1995. 